GRASAS Y ACEITES 72 (1)

January-March 2021, e392

ISSN-L: 0017-3495

https://doi.org/10.3989/gya.1021192

\title{
Preliminary investigation of possible effects of mineral clay treatment applied to oils produced from olives: focus on moisture removal and compositional changes
}

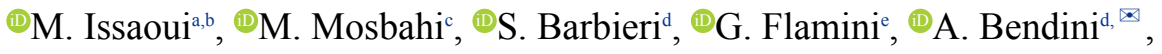 \\ $\oplus^{\circledR R}$. Ascrizzie, ${ }^{\oplus}$ T. Gallina Toschi ${ }^{\mathrm{d}}$ and ${ }^{\oplus} \mathrm{M}$. Hammami ${ }^{\mathrm{a}}$

\begin{abstract}
${ }^{a}$ Lab-NAFS ‘Nutrition - Functional Food \& Vascular Health', Faculty of Medicine, University of Monastir, 5019 Monastir, Tunisia 'Laboratory of Georessources (code: LR15CERTE01), CERTE, TechnopoleBorjCedria, BP273, 8020 Soliman, Tunisia ¿Department of Agricultural and Food Sciences (DiSTAL), University of Bologna, Piazza Goidanich 60, 47521 Cesena (FC), Italy 'Dipartimento di Farmacia, via Bonanno 6, 56126 Pisa, Italy
\end{abstract} \\ ${ }^{b}$ Departement of Biotechnology, Faculty of Science and Technology of SidiBouzid, University of Kairouan, 9100 SidiBouzid, Tunisia. \\ ${ }^{\bowtie}$ Corresponding author: alessandra.bendini@unibo.it
}

Submitted: October 04, 2019; Accepted: January 20, 2020; Published online: February 24, 2021

\begin{abstract}
SUMMARY: In this preliminary study, two non-filtered virgin olive oils (one freshly produced VOO-N; one VOO-O stored for one year) were subjected to moisture removal with mineral clay (raw or activated) and analyses were performed to attest possible effects on the quality of the product. The results demonstrated that the treatment of oil with mineral clay at $36-38{ }^{\circ} \mathrm{C}$ had no negative effect on the basic quality parameters or on the volatile comound profile. On the other hand, a significant decrease in the water amount as well as in pigments was observed in the samples subjected to this kind of treatment, in particular with raw clay. Regarding the colour measurement, the lightness $(L)$ as well as the consumers' acceptability exhibited a marked increase when oils were treated with raw clay.
\end{abstract}

KEYWORDS: Colorimetric measurement; Consumers' acceptability; Mineral clay; Moisture; pigments; Quality parameters; Virgin olive oil; Volatile compounds

RESUMEN: Investigación preliminar sobre los posibles efectos del tratamiento con arcilla mineral aplicado a aceites producidos a partir de aceitunas: enfoque sobre la eliminación de humedad y cambios en la composición. En este estudio preliminar, dos aceites de oliva vírgenes no filtrados (uno VOO-N recién producido y el otro, VOO-O almacenado durante un año) fueron sometidos a la eliminación del contenido de humedad con arcilla mineral (cruda o activada) y se realizaron análisis para atestiguar posibles efectos sobre la calidad del producto. Los resultados demostraron que el tratamiento del aceite con arcilla mineral, realizado a $36-38{ }^{\circ} \mathrm{C}$, no tuvo consecuencias negativas en los parámetros básicos de calidad y en el perfil de los compuestos volátiles. Por otro lado, se observó una disminución significativa en la cantidad de agua y en los pigmentos en las muestras sometidas a este tipo de tratamiento, en particular con arcilla cruda. Con respecto a la medida del color, luminosidad (L) y aceptabilidad de los consumidores mostraron un aumento notable cuando los aceites se trataron con arcilla cruda.

PALABRAS CLAVE: Aceite de oliva virgen; Aceptabilidad de los consumidores; Arcilla mineral; Compuestos volátiles; Humedad; Medida colorimétrica; Parámetros de calidad; Pigmentos

Citation/Cómo citar este artículo: Issaoui M, Mosbahi M, Barbieri S, Flamini G, Bendini A, Ascrizzi R, Gallina Toschi T, Hammami M. 2021. Preliminary investigation of the possible effects of mineral clay treatment applied to oils produced from olives: focus on moisture removal and compositional changes. Grasas Aceites 72 (1), e392. https://doi.org/10.3989/gya.1021192

Copyright: (C2021 CSIC. This is an open-access article distributed under the terms of the Creative Commons Attribution 4.0 International (CC BY 4.0) License. 


\section{INTRODUCTION}

Extra virgin olive oil (EVOO) is the highest quality category for virgin olive oils (VOO) as exhibited by the International Olive Council (IOC, 2015). EVOO is produced from fresh and intact olives using only mechanical/physical extraction processes and without heating (less than $30{ }^{\circ} \mathrm{C}$ ), the addition of food additives or adjuvants or blending with other edible oils (IOC, 2015). For this reason, it deserves the qualification of "olive juice". EVOO exhibites a high shelf life in comparison to other oils and fats thanks to its characteristic composition in fatty acids, and, as recognized in many studies, the presence of peculiar antioxidants (Bendini et al., 2007; Issaoui et al., 2009). Yet, storage conditions are important factors that can affect the conservation period of the $\mathrm{VOO}$ and several factors, such as temperature, light, oxygen moisture and presence of microorganisms have to be carefully controlled (Stefanoudaki, 2010). According to the main international standards (Codex Alimentarius, International Olive Council (IOC), European Commission (EC)) the quality of VOO is based on several parameters, such as the percentage of free fatty acids, the peroxide value, the spectrophotometric absorbances in the UV region, the sensory analysis and the fatty acid ethyl ester content (Conte et al., 2019). In order to evaluate olive oil quality, the Codex Alimentarius and IOC have also included the determinations of insoluble impurities, moisture percentage, some metals and unsaponifiable matter (CAC, 2003; Boskou 2006; IOC, 2015). In general, for food safety and shelf life validation of the food product, information about water activity can be considered very useful. Water activity (Aw) is a measurement of the free water in a sample and ranges between 0 (bone dry) to 1.0 (pure water), providing valuable information about the possible effects of chemical-physical modifications as well as microbial growing. Together, water activity and moisture content give a more complete picture of the food stability status (Isengard, 2001).

The color of the foodstuff is one of the first sensory attributes evaluated by consumers (Pagliarini et al., 1994). VOO has a typical color, which ranges from the different shades of yellow to deep green depending on the olive variety, the agricultural practices such as irrigation, the maturation index and the oil extraction process (Escolar et al., 2007; Lazzerini and Domenici, 2017).The VOO color is linked to the presence of two main classes of pigments which are transferred from the olive fruit to the VOO during the extraction process: the green chlorophylls and the yellow and orange carotenoids (Cerretani et al., 2008). Thus, the consumer may feel attracted by green oils, richer in chlorophylls, or more yellowish oils, richer in carotenoids and pheophytins. The color determination is not included among the criteria used to determine VOOs quality grade but it could represent one of the major purchase drivers among consumers.

Clarification and/or filtration are the latter steps of the production of VOO before bottling which can be applied to eliminate water and suspended particles that still remain in the oily layer. The mechanical process, mainly vertical centrifugation, is the most commonly used clarification method. This system requires the use of lukewarm water, in a ratio variable from $1: 1$ to $1: 2 \mathrm{v} / \mathrm{v}$ oillwater. The addition of water to the centrifuge system leads to the production of an effluent with high contaminant activity (from 20 to $40 \mathrm{~L}$ of liquid by-product per $100 \mathrm{~kg}$ of fruits). The second disadvantage of this system is its impact on the olive oil quality by changing its aromatic bouquet and decreasing its amount of phenolic molecule contents and consequently its sensory attributes (mainly bitterness) and shelf life (Uceda, Jimenez and Beltran, 2006; Garcia et al., 2001; Masella et al., 2009; Gila et al., 2017). However, at the industrial level, a filtration process is generally applied to cloudy VOO for removing suspended solids and humidity before storage or bottling steps. Conventional filtration systems use organic or inorganic filter aids, such as diatomaceous earth and cellulose fibers, in conjunction with filtration equipment (tanks or presses) (Lozano-Sanchez et al., 2010; Masella et al., 2011). Previous studies (Lozano-Sánchez et al., 2007; Gómez-Caravaca et al., 2007) remarked that the filtration step may either positively or negatively affect the stability, phenolics, volatiles, pigments and the sensory proprieties of olive oil and discussed the possible use of different types of filtering systems.

Clay minerals, thanks to specific absorbtion properties, are used in the purification and clarification of vegetable oils (Mosbahi et al., 2017; Mosbahi et al., 2008). Based on the recent research of Mosbahi et al., (2017), satisfactory bleaching of $100 \mathrm{~mL}$ of soybean oil was obtained with $0.75 \%$ of mineral clay under stirring at $110-130{ }^{\circ} \mathrm{C}$. The activated clay used presented a higher capacity to clarify soybean oil than those 
given by commercialized products used for the same purpose (Mosbahi et al., 2017).

The main aims of the present research were: (i) to study the the application of raw and activated mineral clay for removing the moisture in oils produced from olives (ii) to investigate the possible effects of this kind of treatment performed at $36-38{ }^{\circ} \mathrm{C}$ in terms of basic quality parameters (such as free acidity and peroxide value), oxidative stability, volatile compounds, pigments and color (iii) to evaluate consumer acceptance in terms of the appearance characteristic (color).

\section{MATERIAL AND METHODS}

\subsection{Mineral material}

The raw clay used for the basic activation of clay and the clarification processes of the oil were carried out as previously described (Mosbahi et al., 2017). The clay from Chouabine formation (Ypresian) was collected from the OuedErrizgui section at Jebel Meheri El Jebbes, Central Tunisia. The origin, specific surface, porosity and other chemical compositions of the clay have been described in detail by Mosbahi et al., (2017). The raw clays were dispersed in water for a few days and screened through a sieve of $40 \mu \mathrm{m}$ to remove impurities, and then dried at $60{ }^{\circ} \mathrm{C}$ for several days. For the clay activation, a mixture of $15 \mathrm{~g}$ of sieved clay and $5 \% \quad \mathrm{Na}_{2} \mathrm{CO}_{2}$ was soaked in $150 \mathrm{~mL}$ of distilled water and stirred continuously for 30 minutes.

\subsection{VOO samples}

The present study was applied to two samples of unfiltered virgin olive oil. The first sample, coded VOO-N, was produced by the extraction of Chemlali olives using a continuous system equipped with a three-phase decanter (freshly produced VOO-N). The second sample, coded VOO-O, was a virgin olive oil which had been stored for one year, produced during the previous season and purchased in bulk. These samples were submitted to clarification with raw clay $(C)$ and with activated clay (A), stored at $-20{ }^{\circ} \mathrm{C}$ and kept in the dark before analysis. Control samples (T) for each untreated VOO sample were also analyzed. Analytical determinations were performed in triplicate. The treatment was carried by the introduction of $0.75 \mathrm{~g}$ of clay (raw or activated) mixed with $100 \mathrm{~mL}$ of olive oil. The mixture was continuously stirred for $30 \mathrm{~min}$ at 36-38 ${ }^{\circ} \mathrm{C}$ and then filtered. The procedure was repeated many times until obtaining the amount needed for analysis (around $2 \mathrm{~L}$ ).

\subsection{Basic quality parameters}

Free acidity (FA, given as the \% of oleic acid) and peroxide value (PV), expressed as milli equivalents of active oxygen per kilogram of oil, meq $\mathrm{O}_{2} / \mathrm{kg}$, were evaluated according to the official methods (EEC 2568/91 and following amendments). A sensory analysis was performed by the professional panel of the Office national de l'huile (ONH), composed of a fully trained assessors trained and recognized by the International Olive Council (IOC). Sensory analysis was carried out as described in IOC, 2018.

\subsection{Water activity and moisture content}

Water activity is defined as the ratio between the vapor pressure of a food system and the saturation vapor pressure of distilled water under identical conditions. Water activity (Aw) was determined at $25{ }^{\circ} \mathrm{C}$ using a NOVASINA aw Sprint TH-500 apparatus (Novasina, pfäffikon, Switzerland).

Moisture and volatile matter contents were determined according to the method described in ISO 662:1998 (heating at $103{ }^{\circ} \mathrm{C} \pm 2{ }^{\circ} \mathrm{C}$ until stable weight).

\subsection{Oxidative stability index}

The evaluation of the oxidative stability index was carried out by the Rancimat apparatus (Mod. 743, Metrohm $\Omega$, Switzerland). Briefly, $3 \mathrm{~g}$ of each sample were heated to $120{ }^{\circ} \mathrm{C}$ and submitted to an air flow of $20 \mathrm{~L} \cdot \mathrm{h}^{-1}$. Stability was expressed as induction time in hours (h).

\subsection{Color measurement}

The color of the different samples was measured using a chromometer (Lovibond PFX-195 Tintometer). CIE 1976 L*a*b* (CIELAB), based on the opponent color theory, was applied as the color scale to study changes in the color: $\mathrm{L}^{*}$ (lightness), refers to the lightness of the samples and ranges from black $=0$ to white $=$ 100; a negative value for $\mathrm{a}^{*}$ (redness) indicates 
green, while a positive one indicates a red-purple color. Positive $b^{*}$ (yellowness) indicates yellow, and a negative blue color. Oil color was measured by placing olive oil in quartz cuvettes in the color instrument. The instrument was standardized with a white and black ceramic plate. Hue angle (Equation 1) and chroma (Equation 2) were calculated using $\mathrm{L}^{*}, \mathrm{a}^{*}$, and $\mathrm{b}^{*}$ values:

$$
\begin{gathered}
\text { Hue angle }=\frac{b^{*}}{a^{*}} \\
\text { Chroma }=\sqrt{a^{*^{2}+b^{* 2}}} \quad \text { (Equation 1) }
\end{gathered}
$$

The chromameter was used for measuring reflected color and color differences among the samples subjected or not to treatment with mineral clay. Three readings were taken for each sample. Characterization of olive oil color was carried out as described previously by Gámbaro et al., (2014). Based on the value for lightness, the degree of clarity ( $\mathrm{L}$ value between $50-60$ gives a medium clarity appearance; $\mathrm{L}$ value between 65 and 75 gives a high clarity appearance; $\mathrm{L}$ value higher than 80 gives a very high clarity appearance) was determined.

\subsection{Determination of pigments}

Olive oil pigments represtented mainly by carotenoids and chlorophylls $(\mathrm{mg} / \mathrm{kg}$ oil) were determined at $470 \mathrm{~nm}$ and $670 \mathrm{~nm}$, respectively, in cyclohexane, using specific extinction values, according to the method of Minguez-Mosquera et al., (1991).

The total content in pigments was determined as the sum of the chlorophyll and carotenoid concentrations in the oil, as previously described by Gámbaro et al., (2014).

\subsection{Volatile compound analysis}

The aromatic profile of the samples was studied and analysed according to the protocol previously detailed in Issaoui et al., (2019). A Supelco Solid Phase Micro Extraction (SPME) fiber coated with polydimethylsiloxane (PDMS, $100 \mu \mathrm{m}$ ) was used. $2 \mathrm{~mL}$ of sample were placed in a $5 \mathrm{~mL}$ glass vial and, after equilibration (30 $\mathrm{min})$, the fiber was inserted into the headspace of the sample for $50 \mathrm{~min}$ at room temperature. Once sampling was finished, the fiber was withdrawn into the needle and transferred and desorbed in the injection port of the GC-MS system. SPME sampling was performed using the same new fiber, precon- ditioned according to the manufacturers' instructions for all the analyses. SPME sampling and desorption conditions were identical for all the samples. Blanks were performed before each first SPME extraction and randomly repeated during each series. Quantitative comparisons of the relative peaks areas were made between the same chemicals in the different samples. A GCEIMS analysis was carried out with a Varian CP 3800 gas-chromatograph equipped with a DB-5 Capillary column $(30 \mathrm{~m} \times 0.25 \mathrm{~mm}, 0.25 \mu \mathrm{m}$ coating thickness) and a Varian Saturn 2000 ion trap mass detector. Injector and transfer line temperatures were $250{ }^{\circ} \mathrm{C}$ and $240{ }^{\circ} \mathrm{C}$, respectively; oven temperature was programmed from $60{ }^{\circ} \mathrm{C}$ to $240{ }^{\circ} \mathrm{C}$ at $3{ }^{\circ} \mathrm{C} \mathrm{min}^{-1}$; carrier gas, helium

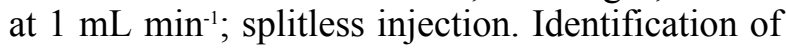
compounds was based on comparison of the retention times with those of pure standards, comparing their linear retention indices relative to the series of $n$-hydrocarbons, using the information from the National Institute of Standards and Technology library (NIST 2014 and ADAMS) and homemade library mass spectra built from pure substances and components of known mixtures and MS literature data (Adams, 1995; Jennings and Shibamoto, 1980; Davies, 1990; Massada, 1976; Stenhagen, Abrahamsson, and MC Lafferty, 1974; Swigar and Maestri, 2006).

\subsection{Acceptance test}

A total of 33 subjects participated in the study and were interviewed to investigate the color liking of the samples. The group of participants came from different regions of Tunisia and was selected using predetermined screening criteria based on level of education (high or incomplete), purchasing and consumption frequency, as well as familiarity with VOOs in Tunisia. Participants were asked to evaluate the samples according to their preference before and after the clarification process with raw and activated clay by checking the color of the oil and to express their degree of liking using a 9-point hedonic scale (scores: like extremely: 9; like very much: 8 ; like moderately: 7; like slightly: 6; neither like nor dislike: 5; dislike slightly 4; dislike moderately: 3 ; dislike very much: 2; dislike extremely: 1) (Peryan and Girardot, 1952). Each consumer had to complete a questionnaire on personal data and other information (age, gender, region of origin, socioprofessional category, and consumption frequency 
of EVOO). Samples (50 mL) were served at room temperature in transparent glass bottles coded with three-digit numbers and presented to consumers randomly, under blind conditions.

\subsection{Statistical analysis}

Data were processed by the SPSS statistical package (Version 12.00 for Window, SPSS Inc. Chicago, Illinois, 2003). The significance of difference at a 5\% level among means was determined by one-way ANOVA, using Tukey's test. For the acceptance sensory test, to check whether a difference among samples existed, ANOVA and the F-test were used. Duncan's multiple range test was used to obtain all pair wise comparisons among sample means. A correlation analysis was performed by employing Person's test.

\section{RESULTS AND DISCUSSION}

Results related to basic quality parameters (free acidity, peroxide value and sensory analysis) of the two samples, freshly produced VOO-N and the one stored for one year, VOO-OT, before and after the treatment with raw and activated mineral clay, are shown in Table 1 . The freshly produced oil treated with raw and activated clay (VOO-NC and VOO-NA) remained practically unchanged in comparison to the non-treated one (VOO-NT) and the oil stored for one year after treatment (VOO$\mathrm{OC}$ and VOO-OA) showed only very slight differences compared to the control (VOO-OT). All samples, before and after the treatment with raw and activated mineral clay, belonged to the same quality grade, virgin olive oil, due to the presence of a mean perceived sensory defect with intensity below 3.5 and of a percentage of free acidity between $0.8 \%$ and $2 \%$ (peroxide number was below 20 meq per $\mathrm{kg}$ of oil in all samples).

The sensory analysis by panel test was applied to the samples before and after the treatment in order to evaluate the possible effect of the clay treatment on the presence of positive and negative attributes (EU regulations, 2011 and IOC, 2015). The freshly produced oil VOO-N had a higher fruitiness perception compared to the sample stored for one year VOO-O (4vs 1). However, the two samples were similar in terms of low intensities of bitterness and pungency. The VOO$\mathrm{N}$ and the VOO-O, before and after treatment, were characterized by the presence of a rancid defect, perceived by lower intensity in the case of the freshly produced sample. The oil stored for one year also showed fusty-muddy as a secondary defect (Table 1). The obtained results exhibited that the clay treatment (raw and activated) had no significant effect on sensory characteristics.

Water activity is considered one of the most important parameters in food preservation. In fact, water is very important for the life of microrganisms and the major enzymatic activities, thus influencing the stability and the shelf-life of food products (Mathlouthi, 2001; FAO, 2003). This parameter is also interesting from the commercial point of view and it is legally regulated (Isengard, 2001). Humidity is indeed among VOO's worst enemies. It negatively affects the stability of the product against hydrolytic and oxidative degradations, the sensory profile and consequently its shelf-life. The IOC (2015) sets the moisture content at lower or equal to $0.2 \%$ $(\mathrm{m} / \mathrm{m})$ for edible virgin olive oil.

As expected, the highest water content in all samples (moisture, Table 1) was recorded in nontreated oils. In particular, the samples exhibited elevated moisture contents ranging from 2 to $0.9 \%(\mathrm{~m} / \mathrm{m})$, respectively, for (VOO-NT) and (VOO-OT). After the process with raw and activated mineral clay, values markedly decreased: the moisture content significantly lowered for both kinds of oils in the case of the treatment with raw clay (VOO-N moved from 2 to $0.3 \%$ and VOO-O decreased from 0.9 to $0.5 \%$ ). A significant reduction was also observed when the freshly produced VOO-N was treated with activated clay (from $2 \%$ to $0.2 \%$ ) but not in the case of sample stored for one year VOO-O. The Aw of VOO-N and VOO-O, when samples were treated with raw clay, significantly decreased from 0.601 to 0.449 , and from 0.626 to 0.422 , respectively; whereas the activated clay did not evidence the same effect.

No significant differences in terms of oxidative stability were shown after the treatment with mineral clay (for both types of clay) compared to the untreated one (Table 1). However, it has to be considered that the values were very low, in agreement with the fact that the oils presented sensory rancidity and low intensities of bitter and pungent positive attributes that, as known, are strictly related to the phenolic content.

Consumers perceive VOO color and may dislike oil only based on this parameter, even though the rest of its sensory attributes are suitable (Gámbaro et al., 2014). Color seems to be an important factor in consumers' choice of virgin 
TABLE 1. Basic quality parameters (free fatty acid FA, peroxide value PV, sensory analysis), colorimetric measurements ( $\mathrm{L}^{*}$ lightness, a* redness and $\mathrm{b}^{*}$ yellowness), water activity, moisture content, oxidative stability index and pigments for untreated freshly produced VOO (VOO-NT) and one after a year of storage VOO (VOO-OT).

\begin{tabular}{|c|c|c|c|c|c|c|c|}
\hline \multicolumn{2}{|l|}{ Samples } & \multicolumn{3}{|c|}{ VOO-N } & \multicolumn{3}{|c|}{ VOO-O } \\
\hline Treatment & & $\mathbf{T}$ & $\mathbf{C}$ & $\mathbf{A}$ & $\mathbf{T}$ & $\mathbf{C}$ & $\mathbf{A}$ \\
\hline FA (\%) & & $1.5^{\mathrm{a}}$ & $1.3^{\mathrm{a}}$ & $1.5^{\mathrm{a}}$ & $1.1^{\mathrm{x}}$ & $0.8^{\mathrm{y}}$ & $0.8^{\mathrm{y}}$ \\
\hline \multirow[t]{3}{*}{$\mathrm{PV}\left(\mathrm{meqO}_{2} / \mathbf{k g}\right)$} & & $3.7^{\mathrm{a}}$ & $4.6^{\mathrm{a}}$ & $3.2^{\mathrm{a}}$ & $12.5^{\mathrm{x}}$ & $9.3^{y}$ & $9.3^{y}$ \\
\hline & Fruity & $4.0^{\mathrm{a}}$ & $4.0^{\mathrm{a}}$ & $4.0^{\mathrm{a}}$ & $1.0^{\mathrm{x}}$ & $1.0^{\mathrm{x}}$ & $1.0^{\mathrm{x}}$ \\
\hline & Bitter & $2.0^{\mathrm{a}}$ & $2.0^{\mathrm{a}}$ & $2.1^{\mathrm{a}}$ & $2.5^{\mathrm{x}}$ & $2.0^{\mathrm{x}}$ & $1.0^{\mathrm{y}}$ \\
\hline \multirow[t]{4}{*}{ Sensory Analysis } & Pungent & $1.0^{\mathrm{a}}$ & $1.0^{\mathrm{a}}$ & $1.0^{\mathrm{a}}$ & $1.0^{\mathrm{x}}$ & $1.0^{\mathrm{x}}$ & $1.0^{\mathrm{x}}$ \\
\hline & Fusty/muddy & n. $\mathrm{p}^{\mathrm{a}}$ & n.p $p^{a}$ & n. $\mathrm{p}^{\mathrm{a}}$ & $0.6^{x}$ & $0.9^{\mathrm{x}}$ & n.p..$^{y}$ \\
\hline & Rancid & $0.9^{\mathrm{a}}$ & $0.6^{\mathrm{a}}$ & $0.8^{\mathrm{a}}$ & $2.0^{\mathrm{x}}$ & $1.9^{\mathrm{x}}$ & $2.1^{x}$ \\
\hline & $L$ & $63.6^{\mathrm{b}}$ & $90.1^{\text {a }}$ & $89.1^{\mathrm{a}}$ & $88.0^{\mathrm{y}}$ & $91.0^{x}$ & $90.7^{x}$ \\
\hline \multirow[t]{2}{*}{ Colorimetric parameters } & $a^{*}$ & $-8.4^{\mathrm{a}}$ & $-13.6^{b}$ & $-13.4^{b}$ & $-11.7^{\mathrm{x}}$ & $-11.9^{\mathrm{x}}$ & $-11.7^{\mathrm{x}}$ \\
\hline & $b^{*}$ & $43.1^{\mathrm{a}}$ & $41.5^{\mathrm{a}}$ & $43.1^{\mathrm{a}}$ & $42.2^{x}$ & $41.5^{\mathrm{x}}$ & $41.9^{x}$ \\
\hline Water activity & & $0.601^{\mathrm{a}}$ & $0.449^{b}$ & $0.610^{\mathrm{a}}$ & $0.626^{x}$ & $0.422^{z}$ & $0.591^{y}$ \\
\hline Moisture content (\%) & & $2.0^{\mathrm{a}}$ & $0.3^{\mathrm{b}}$ & $0.2^{\mathrm{c}}$ & $0.9^{\mathrm{x}}$ & $0.5^{z}$ & $0.8^{y}$ \\
\hline \multirow[t]{2}{*}{ Oxidative stability index (h) } & & $1.3^{\mathrm{ab}}$ & $1.1^{\mathrm{b}}$ & $1.6^{\mathrm{a}}$ & $1.0^{\mathrm{x}}$ & $1.0^{\mathrm{x}}$ & $1.1^{\mathrm{x}}$ \\
\hline & Chlorophylls & $7.73^{\mathrm{a}}$ & $1.29^{\mathrm{b}}$ & $0.91^{\mathrm{c}}$ & $2.58^{\mathrm{x}}$ & $<\mathrm{LOQ}^{\mathrm{Y}}$ & $<\mathrm{LOQ}^{\mathrm{Y}}$ \\
\hline \multirow[t]{2}{*}{ Pigments (mg/kg) } & Carotenoids & $3.18^{\mathrm{a}}$ & $0.83^{\mathrm{b}}$ & $0.88^{\mathrm{b}}$ & $1.19^{\mathrm{x}}$ & $0.17^{y}$ & $0.24^{y}$ \\
\hline & Total pigments & $10.91^{\mathrm{a}}$ & $2.12^{\mathrm{b}}$ & $1.79^{\mathrm{b}}$ & $3.77^{\mathrm{x}}$ & $0.17^{\mathrm{y}}$ & $0.24^{y}$ \\
\hline
\end{tabular}

The two samples were purchased in bulk and treated with raw clay (VOO-NC, VOO-OC) and activated clay (VOO-NA, VOO-OA), respectively. Positive sensory attributes and the main perceived defects are expressed as median values of intensities. n.p. not perceived. Values in the same row with different superscript letters represent significant differences between treatments for the same sample at $p<0.05$ by Tukey's test $(\mathrm{n}=3)$.

olive oil, often being the key criterion for preference. The typical green color of virgin olive oil comes from chlorophyll; while the yellow one is the result of the presence of carotenoids. The comparison of color data between samples before and after treatement with mineral clay is reported in Table 1 . The ANOVA test showed a statistically significant influence of the clarification process on some colorimetric parameters, in particular for the freshly produced oil. The treatement significantly increased the lightness $(L)$ (VOO-NT moved from 63.6 to 90.1 and 89.1 for oil treated with raw and activated clay, respectively) and decreased the greenness $\left(-\mathrm{a}^{*}\right)$ (the $\mathrm{a}^{*}$ value for VOO-NT was -8.4 and after treatement with raw and activated clay, it lowered to -13.6 and -13.4 , respectively). On the other hand, yellowness $\left(b^{*}\right)$ was not influenced and no statistically significant differences were observed between treated and untreated samples (Table 1).
The modification of the colorimetric parameters in the case of VOO-O is not highly remarkable in comparison to the case of VOO-N. This may be explained by the lowest quantities of pigments present in the product that are subjected to degradation during storage. The results, depicted in Table 1, demonstrated a marked decrease in chlorophylls and carotenoids after the treatement process with raw and activated mineral clay for both the oils, but the pigment concentrations in VOO-O before the treatment was substantially lower than VOO-N due to the long storage period. Generally, the treatment with mineral clay was more effective on chlorophylls than on carotenoids, in agreement with the colorimetric values. These observations were in agreement with Cerretani et al., (2008), who reported that the luminosity values $\left(\mathrm{L}^{*}\right)$ increased with the reduction in the pigment contents in the oils. In fact, it was noticed that the color of the oil, 
mainly the green one, which is related to the amount of chlorophylls, decreased with the increase in lightness ( $\left.\mathrm{L}^{*}\right)$ in the samples. According to Cerretani et al., (2008), significant correlations between the content in pigments and the tristimulus color measurement were obtained, specifically the total carotenoids $v s$ the values for $\mathrm{a}^{*}$ (green area) and $\mathrm{b}^{*}$ (yellow area) $v s \mathrm{a}^{*} / \mathrm{b}^{*}$ (green/yellow balance).

The volatile substances identified and quantified in the headspace of the VOOs before and after the treatment with mineral clay, together with those for raw clay, activated clay, and used clay impregnated with olive oil were studied (Table 2).

Virgin olive oil has a highly distinctive flavor due to specific volatile organic compounds belonging to several chemical classes, namely aliphatic and aromatic hydrocarbons, aliphatic and triterpene alcohols, aldehydes, ketones, ethers, esters and furan and thiophene derivatives (Kiritsakis et al., 1998). The main objective of this research was to study the behavior of clay towards olive oil, mainly whether it can adsorb oxidation compounds and to determine the degree of permeability/impermeability of clay in VOOs.

TABLE 2. Volatile compounds, expressed in \%, of freshly produced VOO-N and VOO-O before (T) and after clarification with raw clay (C) and activated clay $(A)$; raw clay $(\mathrm{Cr})$, activated clay $\left(\mathrm{C}_{\mathrm{rA}}\right)$, raw clay with VOO-N $\left(\mathrm{C}_{\mathrm{NB}}\right)$, raw clay with VOO-O $\left(\mathrm{C}_{\mathrm{RO}}\right)$.

\begin{tabular}{|c|c|c|c|c|c|c|c|c|c|c|}
\hline \multirow{2}{*}{$\begin{array}{l}\text { Samples } \\
\text { Treatment }\end{array}$} & \multicolumn{3}{|c|}{ VOO-N } & \multicolumn{3}{|c|}{ VOO-O } & \multicolumn{4}{|c|}{ Clay } \\
\hline & $\mathbf{T}$ & $\mathbf{C}$ & $\mathbf{A}$ & $\mathbf{T}$ & $\mathbf{C}$ & $\mathbf{A}$ & $\mathbf{C}_{\mathrm{r}}$ & $\mathrm{C}_{\mathrm{ra}}$ & $\mathbf{C}_{\mathrm{NB}}$ & $\mathbf{C}_{\mathrm{ro}}$ \\
\hline \multicolumn{11}{|c|}{ Markers of LOX pathway (expressed in \%) } \\
\hline Hexanal & $6.3^{\mathrm{a}}$ & $6.9^{\mathrm{a}}$ & $6.7^{\mathrm{a}}$ & $6.3^{x}$ & $6.1^{\mathrm{x}}$ & $5.3^{\mathrm{x}}$ & nd & nd & $19.9^{1}$ & $18.9^{1}$ \\
\hline (E)-2-hexenal & $47.7^{\mathrm{b}}$ & $55.0^{\mathrm{a}}$ & $57.2^{\mathrm{a}}$ & $4.1^{x}$ & $4.7^{\mathrm{x}}$ & $5.0^{\mathrm{x}}$ & nd & nd & $0.1^{2}$ & $0.5^{1}$ \\
\hline (Z)-2-hexen-1-ol & $10.0^{\mathrm{a}}$ & $10.3^{\mathrm{a}}$ & $10.3^{\mathrm{a}}$ & nd & nd & nd & nd & nd & nd & nd \\
\hline 1-hexanol & nd & nd & nd & $29.1^{y}$ & $31.6^{x}$ & $31.8^{\mathrm{x}}$ & nd & nd & $0.5^{1}$ & $0.5^{1}$ \\
\hline 3-ethyl-1,5-octadiene* & $1.2^{\mathrm{a}}$ & $1.1^{\mathrm{a}}$ & $1.1^{\mathrm{a}}$ & $1.0^{\mathrm{x}}$ & $0.8^{\mathrm{x}}$ & $0.8^{\mathrm{x}}$ & nd & nd & nd & nd \\
\hline 3-ethyl-1,5-octadiene* & $0.8^{\mathrm{a}}$ & $0.8^{\mathrm{a}}$ & $0.8^{\mathrm{a}}$ & $1.3^{x}$ & $1.2^{\mathrm{x}}$ & $1.2^{\mathrm{x}}$ & nd & nd & nd & nd \\
\hline \multicolumn{11}{|c|}{ Markers of lipid oxidation (expressed in \%) } \\
\hline Heptanal & nd & nd & nd & nd & nd & nd & nd & nd & $1.5^{1}$ & $0.7^{2}$ \\
\hline (Z)-2-heptenal & nd & nd & nd & nd & nd & nd & nd & nd & 0.1 & $0.4^{1}$ \\
\hline (E)-2-heptenal & $1.5^{\mathrm{b}}$ & $3.2^{\mathrm{a}}$ & $2.2^{\mathrm{ab}}$ & $1.4^{\mathrm{x}}$ & $2.1^{\mathrm{x}}$ & $1.7^{\mathrm{x}}$ & nd & nd & $2.9^{2}$ & $8.0^{1}$ \\
\hline Octanal & $0.4^{\mathrm{b}}$ & $1.1^{\mathrm{a}}$ & $0.5^{\mathrm{b}}$ & nd & $0.6^{y}$ & $0.8^{\mathrm{x}}$ & nd & nd & $13.6^{1}$ & $3.3^{2}$ \\
\hline (Z)-2-octenal & nd & nd & nd & nd & nd & nd & nd & nd & $1.6^{2}$ & $5.6^{1}$ \\
\hline (E)-2-octenal & nd & nd & nd & nd & $0.5^{\mathrm{x}}$ & nd & nd & nd & $9.0^{2}$ & $15.4^{1}$ \\
\hline Nonanal & $2.4^{\mathrm{b}}$ & $3.3^{\mathrm{a}}$ & $3.3^{\mathrm{a}}$ & $1.7^{2}$ & $3.0^{\mathrm{x}}$ & $2.1^{y}$ & nd & nd & $4.0^{1}$ & $1.6^{2}$ \\
\hline (Z)-2-nonenal & nd & nd & nd & nd & nd & nd & nd & nd & $0.3^{1}$ & $0.4^{1}$ \\
\hline (E)-2-nonenal & nd & nd & nd & nd & nd & nd & nd & nd & $2.2^{1}$ & $1.7^{1}$ \\
\hline$(E, E)$-2,4-nonadienal & nd & nd & nd & nd & nd & nd & nd & nd & $0.4^{2}$ & $0.8^{1}$ \\
\hline (Z)-2-decenal & nd & nd & nd & nd & nd & nd & nd & nd & $1.0^{1}$ & $0.9^{1}$ \\
\hline (E)-2-decenal & nd & $1.3^{\mathrm{a}}$ & nd & $1.3^{x y}$ & $2.2^{x}$ & $1.8^{\mathrm{x}}$ & nd & nd & $8.7^{1}$ & $7.8^{1}$ \\
\hline$(E, Z)-2,4$-decadienal & nd & nd & nd & $1.1^{\mathrm{x}}$ & nd & nd & nd & nd & $0.1^{1}$ & $0.3^{1}$ \\
\hline (Z)-2-undecenal & nd & nd & nd & nd & nd & nd & nd & nd & $0.7^{1}$ & $0.5^{1}$ \\
\hline (E)-2-undecenal & nd & nd & nd & nd & nd & nd & nd & nd & $4.0^{1}$ & $2.7^{2}$ \\
\hline
\end{tabular}

Values in the same row with different superscript letters represent significant differences between treatments for the same sample at $p<0.05$ by Tukey's test $(\mathrm{n}=3)$. nd, not detected.

* Correct isomer not determined. 
The major volatile compounds in virgin olive oil which contribute to the positive attributes of olive oil aroma (fruity and positive notes) include $\mathrm{C}_{6}$-LOX aldehydes (hexanal, (E)-2-hexenal) and $\mathrm{C}_{6}$-LOX esters (hexyl acetate and (Z)-3-hexenyl acetate). Thus, volatile compounds, which are responsible for most of the sensory properties in virgin olive oils, play a significant role in the evaluation of the overall oil quality and a decisive influence on its acceptability.

Freshly produced VOO-N was characterized by a high percentage of (E)-2-hexenal $(47.7 \%)$ in its profile. On the contrary, VOO-O exhibited a very low content of this compound $(4.7 \%)$. This evidence confirmed the general judgment that (E)-2-hexenal is a biomarker of freshness of olive oil (Issaoui et al., 2015). (Z)-2-hexen-1-ol was also present in a considerable amount in VOO-N. However, 1-hexanol was the predominate compound in the volatile fraction of VOO-O $(29.1 \%)$ and it was not detected in VOO-N. This molecule was the main $\mathrm{C}_{6}$-LOX compound found in the headspace of VOO-O before and after the treatment with mineral clay. On the other hand, this sample, characterized by a sensory rancidity more perceived than in VOO-N, presented a higher content in $(E)$-2-decenal, an unsaturated aldehyde with a low value for odor threshold. It can be noticed that $(E)$-2-hexenal was practically not absorbed by clay. Hence, this compound was present in a percentage of $55.0 \%$ in VOO-N after treatment with raw clay and in a percentage of about $0.1 \%$ in raw clay soaked in VOO-N $\left(\mathrm{C}_{\mathrm{NB}}\right)$ (Table 2). Clay showed a very low permeability to the virgin olive oils' aroma compounds which belonged to the LOX pathway. On the other hand, based on the obtained results, all the compounds resulting from lipid oxidation were swept by the clay to a different degree. It is worth noting that hexanal was the highest absorbed volatile by clay, with a percentage near $20 \%$. This phenomenon may be explained by the fact that hexanal has two sources of production, enzymatic via lipoxygeanse and oxidation and the oil may have remained in the clay after treatment, being subjected to a rapid lipid oxidation before analysis (Table 2). However, the data did not show a clear effect of the treatment with mineral clay on the volatile compounds responsible for the aroma of samples.

As previously mentioned, the colour perception represents one of the most important factors in the consumers' purchase choice, which is sometimes more relevant than other factors, such as package, price, producer, brand, etc (Dekhili et al., 2011). Its importance is probably due to the fact that color is the only sensory attribute that a consumer can generally evaluate during the purchase phase. The color of VOO, which is not significantly related to its quality, may produce expectations. Several investigations have demonstrated how different shadings of VOO color could affect consumer acceptability (Gutiérrez González, 1987; Tous and Romero, 1992; Gambaro et al., 2014). These results are linked with the familiarity of consumers with VOOs produced in different countries and should be taken into account that several agronomic and technological parameters may influence the content in pigments of VOOs and therefore their color. Considering data related to consumer preferences expressed in the hedonic session (Table 3, Figures 1 and 2), the highest color acceptability was obtained for the freshly produced oil treated with raw mineral clay that evidenced a degree of clarity higher than $90 \%$ with a light green shade. However, for both samples, freshly produced and stored for one year, the treatment with raw and activated mineral clay enhanced the color acceptability compared to the untreated oils but only the raw clay reached a very high degree of clarity (Table 3). Figures 1 and 2 show that the more appreciated samples for appearance characteristic (color-liking) were the oils treated with raw mineral clay (VOO-NC and VOO-OC) with 93.9 and $68.7 \%$ of consumers, respectively, with a 7-9 score. Consumers also seem to prefer also the light green of VOO-NC over the deep one of VOO-NT; this result is in agreement with another study that showed that the deep green color of VOOs can negatively affect people (Recchia et al., 2012); whereas its clarity is positively linked with the color liking (McEwan et al., 1994).

\section{CONCLUSIONS}

This preliminary study, performed on two different kinds of unfiltered virgin olive oils, one freshly produced and one stored for one year, demonstrated that the treatment with raw and activated mineral clay, performed under mild conditions (36-38 ${ }^{\circ} \mathrm{C}$ under stirring), did not lead to remarkable changes in the sensory characteristics or the volatile profile nor a modification of hydrolytic or oxidative parameters. On the other hand, its ability to remove moisture and pigments, in particular chlorophylls was proven. This last effect was 
TABLE 3. Color description, degree of clarity and rated color acceptability for the freshly produced VOO (VOO-N) and the one-yearstored VOO (VOO-O).

\begin{tabular}{|c|c|c|c|c|}
\hline \multicolumn{2}{|c|}{ Samples } & \multirow{2}{*}{$\frac{\text { Color Description }}{\text { Green }}$} & \multirow{2}{*}{$\frac{\text { Degree of clarity }}{\text { Medium }(\approx 60)}$} & \multirow{2}{*}{$\frac{\text { Color acceptability }}{5.75^{\mathrm{c}} \pm 0.07}$} \\
\hline & NT & & & \\
\hline \multirow[t]{3}{*}{ VOO-N } & $\mathrm{NC}$ & Light green & Very high $(>90)$ & $8.09^{\mathrm{a}} \pm 0.87$ \\
\hline & NA & Light green & High $(>70)$ & $6.39^{b} \pm 0.61$ \\
\hline & NT & Pale yellow & High $(>70)$ & $5.96^{c} \pm 0.14$ \\
\hline \multirow[t]{2}{*}{ VOO-O } & $\mathrm{NC}$ & Pale yellow & Very high $(>90)$ & $6.78^{b} \pm 0.30$ \\
\hline & NA & Pale yellow & High $(>70)$ & $6.36^{\mathrm{b}} \pm 0.26$ \\
\hline
\end{tabular}

Each sample was purchased in bulk and treated with raw clay (VOO-NC, VOO-OC) and activated clay (VOO-NA, VOO-OA). Results of color acceptability are expressed as mean and standard deviation values and, in addition, different superscript letters represent significant differences between samples at $p<0.05$ by Tukey's test $(\mathrm{n}=3)$.

responsible for the increase in the luminosity value of the oil, a characteristic that seems to positively affect consumers' preference in terms of acceptability.

In general, the comparison of the data obtained after applying raw or activated mineral clay, evidenced a greater efficacy of the raw clay in lowering the humidity (with a concurrent decrease in water activity), enhancing the luminosity as well as the color.

Further studies which include the use of a set of olive oil samples with different physico-chemical and sensory characteristics should be conducted in order to confirm these preliminary results and to check the possible impact of this kind of treatment with mineral clay on some minor (e.g. sterols and phenolic molecules) and major compounds (e.g. glycerides) in the olive oil as well as the main markers of the refining process (e.g. steradiene content, trans-isomers of fatty acids, specific

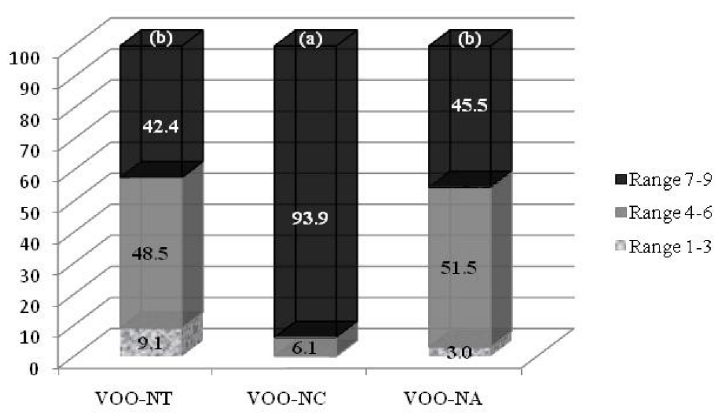

FIGURE 1. Percentages of color-liking for freshly produced VOO (untreated: VOO-NT, clarified with raw clay: VOO-NC and clarified with activated clay: VOO-NA). Acceptance test performed on 33 subjects. Values with different letters (a-b) represent significant differences between samples at $\mathrm{p}<0.05$ by Duncan's test with F value (15.83) $>$ F critical (3.07). absorption in UV of diene and trienes conjugated chromophores). Moreover, specific tests will be performed on selected oil samples to compare the effects of treatment with mineral clay and the current method of filtration. Future results could evidence the feasibility of a potential industrialscale application.

\section{ACKNOWLEDGMENTS}

This research was supported by the Tunisian Ministry of Scientific Research, Technology and Competency Development (UR03ES08). The aromatic analysis was performed at the Dipartimento di Farmacia, Università di Pisa, Italy. Other work was carried out at the Departement of Biotechnology, Faculty of Science and Technology of SidiBouzid, University of Kairouan, SidiBouzid, Tunisia.

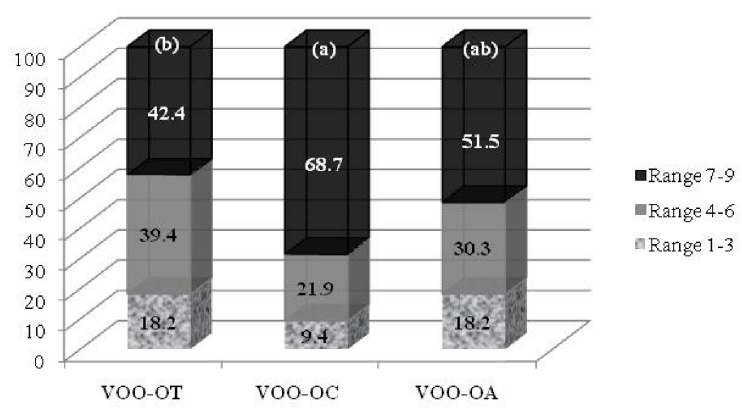

FIGURE 2. Percentages of color-liking for 1 year-stored VOO (untreated: VOO-OT, clarified with raw clay: VOO-OC and clarified with activated clay: VOO-OA). Acceptance test performed on 33 subjects. Values with different letters (a-b) represent significant differences between samples at $p<0.05$ by Duncan's test with F value (1.49) > F critical (3.07). 


\section{REFERENCES}

Adams R.P. 1995. Identification of Essential Oil Components by Gas Chromatography-Mass Spectroscopy. Allured Carol Stream, IL USA

Bendini A, Cerretani L, Carrasco-Pancorbo A, Gómez-Caravaca AM, Segura-Carretero A, Fernández-Gutiérrez A, Lercker G. 2007. Phenolic molecules in virgin olive oils: a survey of their sensoryproperties, health effects, antioxidant activity and analytical methods. An overview of the last decade. Molecules 12, 1679-1719. https://doi.org/10. 3390/12081679

Boskou D. 2006. Olive Oil Composition. In: Olive Oil: Chemistry and Technology. D. Boskou (Ed.) p. 41-7. $2^{\text {nd }}$ edition AOCS Press, Champaign, IL, USA.

CodexAlimentarius Commission (2003). Codex Standard for Olive Oils and Olive Pomaceoils. Codex stan 33-1981. Adoptedin 1981. Revisedin 1989. 2015, 2017. Amendedin 2009, 2013.

Cerretani L, Motilva MJ, Romero MP, Bendini A, Lercker G. 2008. Pigment profile and chromatic parameters of monovarietal virgin olive oils from different Italian cultivars. Eur. Food Technol. 226, 1251-1258. https://doi.org/ 10.1007/s00217-007-0651-7

Conte L, Bendini A, Valli E, Lucci P, Moret S, Maquet A, Lacoste F, Brereton P, GarcíaGonzález D. L, Moreda W, Gallina Toschi T. 2019. Olive Oil Quality and Authenticity: A review of current EU legislation, standards, relevant methods of analyses, their drawbacks and recommendations for the future. Trends Food Sci. Technol. In press. https://doi.org/ 10.1016/j.tifs.2019.02.025

Davies NW. 1990. Gas chromatographic retention indexes of monoterpenes and sesquiterpenes on methyl silicone and carbowax $20 \mathrm{M}$ phases. $J$. Chromatogr. A. 503, 1.

Dekhili S, Sirieix L, Cohen E. 2011. How consumers choose olive oil: The importance of origin cues. Food Qual. Prefer. 22, 757-762. https://doi.org/10.1016/j.foodqual.2011.06.005

Escolar D, Haro MR, Ayuso J. The Color Space of Foods: Virgin Olive Oil. J. Agric. Food Chem. 2007, 55, 6, 2085-2093. https://doi.org/ $10.1021 /$ jf062899v

European Union Commission, Regulation EEC 2568/91. 1991. Characteristics of olive and olive-pomace oils and on their analytical methods. Official Journal of the European Communities, L 248.
European Union Commission, Regulation CE 1989/2003. 2003. Amending Regulation EEC 2568/91. Official Journal of the European Communities, L 295.

European Community, Commission Regulation (2011) 61/2011. Amending Regulation No 2568/91/EEC. Official Journal of the European Communities, January 24, L23, 1-14.

FAO. 2003. Handling and Preservation of Fruits and Vegetables by Combined Methods for Rural Areas. Chapter 3, Agricultural Services Bulletin 149. ISBN 92-5-104861-4.

Gámbaro A, Raggio L, Ellis A.C, Amarillo M. 2014. Virgin olive oil color and perceived quality among consumers in emerging olivegrowing countries. Grasas Aceites 65 (2), 1-7. https://doi.org/10.3989/gya.122213

Gutiérrez González R. 1987. Parámetros de calidad en el aceite de oliva. I. En su utilización en crudo. Pon. 2a. III Simp. Nal. Aceite de Oliva. Jaén.

Gracia A, Brenes M, Martínez F, Alba J, García P, Garrido A. 2001. High performance liquid chromatography evaluation of phenols in virgin olive oil during extraction at laboratory and industrial scale. J. Am. Oil Chem. Soc. 78, 625-629. https://doi.org/10.1007/s11746-0010316-X

Gila AM, Beltran G, Bejaoui MA, Jimenez A. 2017. How clarification systems can affect virgin olive oil composition and quality at industrial scale. Eur. J. Lipid Sci. Technol. 119, 1-8. https://doi.org/10.1002/ejlt.201600479

Gómez-Caravaca AM, Cerratani L, Bendini A, Segura-Carretero A, Fernández-Gutiérrez A, Lercker G. 2007. Effect of filtration systems on the phenolic content in virgin olive oil by HPLC-DAD-MSD. Am. J. Food Technol. 2, 671-678. https://doi.org/10.3923/ajft.2007.671. 678

International Olive Council, Sensory analysis of olive oil-method for the organoleptic assessment of virgin olive oil, COI/T.20/Doc. No. 15/Rev. 10, 2018.

International Olive Council IOC/T.15/Doc No 3/Rev 8 (February 2015). Trade standard applying to olive oils and olive pomace oils.

Isengard HD. 2001. Water content, one of the most important properties of food. Food Control 12, 395-400. https://doi.org/10.1016/ S0956-7135(01)00043-3

Issaoui M, Gharbi I, Flamini G, Cioni PL, Bendini A, Gallina Toschi T, Hammami M. 2015. Aroma compounds and sensory 
characteristics as biomarkers of quality of differently processed Tunisian virgin olive oils. Int. J. Food Sci. Technol. 50 (8), 1764-1770. https://doi.org/10.1111/ijfs.12830

Issaoui $\mathrm{M}$, Bendini A, Souid S, Flamini, G, Barbieri S, Gallina Toschi T, Hammami M. 2019. Flavored olive oils: Focus on their acceptability and thermal stability. Grasas Aceites 70 (1), 293-303. https://doi.org/10.39 89/gya.0224181

Jennings W, Shibamoto T. 1980. Qualitative analysis of flavor and fragrance volatiles by glass capillary chromatography. New York: Academic Press.

Kalua CM, Allen S, Bedgood Jr DR, Bishop AG, Prenzler PD, Robards K. 2007. Olive oil volatile compounds, flavour development and quality: a critical review. Food Chem. 100, 273-286. https://doi.org/10.1016/j.foodchem. 2005.09.059

Lazzerini C, Domenici V. 2017. Pigments in Extra-Virgin Olive Oils Produced in Tuscany (Italy) in Different Years. Foods 6, 25. https:// doi.org/10.3390/foods6040025

López-Feria S, Cárdenas S, García-Mesa JA, Valcárcel M. 2007. Quantification of the intensity of virgin olive oil sensory attributes by direct coupling headspace mass spectrometry and multivariate calibration techniques. J. Chromatogr. A. 1147, 144-152. https://doi.org/10.1016/j.chroma.2007.02.107

Lozano-Sanchez J, Cerretani L, Bendini A, Segura-Carretero A, Fernandez-Gutierrez A. 2010. Filtration process of extra virgin olive oil: Effect on minor components, oxidative stability and sensorial and physico-chemical characteristics. Trends Food Sci. Technol. 21, 201-211. https://doi.org/10.1016/j.tifs.2009.1 2.004

Lozano-Sánchez J, Cerretani L, Bendini A, Gallina-Toschi T, Segura-Carretero A, Fernández Gutiérrez A. 2012. New filtration systems for extra-virgin olive oil: Effect on antioxidant compounds, oxidative stability, and physicochemical and sensory properties. $J$. Agric. Food Chem. 60 (14), 3754-3762. https:// doi.org/10.1021/jf205353b

Masella P, Parenti A, Spugnoli P, Baldi F, Mattei A. 2011. A predictive classification model for the management of virgin olive oil filtration at industrialscale. Sep. Sci. Technol. 46, 1709-1715. https://doi.org/10.1080/0149639 5.2011 .578606
McEwan JA. 1994. Consumer attitudes and olive oil acceptance: the potential consumer. Grasas Aceites 45, 9-15. https://doi.org/10.3989/gya. 1994.v45.i1-2.963

Maheswaran D. 1994. Country of origin as a stereotype: Effects of consumerexpertise and attribute strength on product evaluations. $J$. Consumer Res. 21, 354-365. https://doi.org/ 10.1086/209403

Massada Y. 1976. Analysis of Essential Oils by Gas Chromatography and Mass Spectrometry. New York: Wiley and Sons.

Masella P, Parenti A, Spugnoli P, Calamai L. 2009. Influence of vertical centrifugation on extra virgin olive oil quality. J. Am. Oil Chem. Soc. 86, 1137-1140. https://doi.org/10.1007/ s11746-009-1445-9

Mathlouthi M. 2001. Water content, water activity, water structure and the stability of foodstuffs. Food Control. 12, 409-417. https:// doi.org/10.1016/S0956-7135(01)00032-9

Minguez-Mosquera MI, Rejano L, Gandul B, Sanchez AH, Garrido J. 1991. Color-pigment correlation in virgin olive oil. J. Am. Oil Chem. Soc. 68, 332-336.

Mosbahi M, Tlili A, Khlifi M, Jeddoui Y. 2008. Activation acido-basique des argiles de la formation El Haria du Bassin Meknassy Mezzouna et essais de clarification des huiles neutres de soja. Congrès national de 3èmes journée de l'Association Tunisienne de Géologie Appliquée (ATGA). Mars 2008, Sousse- Tunisie.

Mosbahi M, Tlili A, Khlifi M, Jamoussi F. 2017. Basic activation of lower eocene clay from Mekmassy-Mezzouna basin (centezwestern Tunisia), synthesis of zeolite and clarification of soybean oils. Appl. Clay Sci. 138, 1-11. https://doi.org/10.1016/j.clay.2016.12.011

Pryam DR, Girardot NF. 1952. Advanced taste method. J. Food Eng. 24, 58-61.

Pagliarini E, Stramba P, Semeria L. 1994. Study of the subjective affective meaning and motivational aspects towards extra virgin olive oil. Grasas Aceites 45, 65-67. https://doi.org/ 10.3989/gya.1994.v45.i1-2.973

Uceda M, Jimenez A, Beltran G. 2006. Olive oil extraction and quality. Grasas Aceites 57, 25-31. https://doi.org/10.3989/gya.2006.v57.i 1.19

Recchia A, Monteleone E, Tuorila H. 2012. Responses to extra virgin olive oils in consumers with varying commitment to oils. Food Qual. Prefer. 24, 153-161. https:// doi.org/10.1016/j.foodqual.2011.10.009 
Stefanoudaki E, Williams M, Harwood J. 2010. Changes in virgin olive oil characteristics during different storage conditions. Eur. J. Lipid Sci. Technol. 112 (8), 906-914. https:// doi.org/10.1002/ejlt.201000066

Stenhagen E, Abrahamsson S, Mc Lafferty FW. 1974. Registry of Mass Spectral Data. New York: Wiley and Sons.

Swigar AA, Maestri DM. 2006. The effects of genotype and extraction methods on chemical composition of virgin olive oils from Treslasierra Valley (Cordoba, Argentina). Food Chem. 96, 507-511. https://doi.org/10.1016/ j.foodchem.2005.03.003

Tous Martí J, Romero Aroca A. 1992. Caracterización del color de los aceites de olive vírgenes de cultivares catalanes. Grasas Aceites 43 (6), 347-351. https://doi.org/ 10.3989/gya.1992.v43.i6.1131 